\title{
The diversity of benthic diatoms affects ecosystem productivity in heterogeneous coastal environments
}

\section{Virta, Leena}

2019-09

Virta , L , Gammal , J , Järnström , M , Bernard , G , Soininen , J , Norkko , J \& Norkko , A 2019 , ' The diversity of benthic diatoms affects ecosystem productivity in heterogeneous coastal environments ' , Ecology , vol. 100 , no. 9 , pp. e02765 . https://doi.org/10.1002/ecy.2765

http://hdl.handle.net/10138/305381

https://doi.org/10.1002/ecy.2765

publishedVersion

Downloaded from Helda, University of Helsinki institutional repository.

This is an electronic reprint of the original article.

This reprint may differ from the original in pagination and typographic detail.

Please cite the original version. 


\title{
The diversity of benthic diatoms affects ecosystem productivity in heterogeneous coastal environments
}

\author{
Leena Virta, ${ }^{1,2,6}$ Johanna Gammal, ${ }^{2}$ Marie Järnström, ${ }^{3}$ Guillaume Bernard, ${ }^{4}$ Janne Soininen $(D), 1$ \\ JoAnNa NorkKo, ${ }^{2}$ AND Alf NORKKo ${ }^{2,5}$ \\ ${ }^{1}$ Department of Geosciences and Geography, University of Helsinki, PO Box 64, FIN-00014 Helsinki, Finland \\ ${ }^{2}$ Tvärminne Zoological Station, University of Helsinki, J.A. Palméns väg 260, FI-10900 Hangö, Finland \\ ${ }^{3}$ Environmental and Marine Biology, Åbo Akademi University, Artillerigatan 6, 20520 Åbo, Finland \\ ${ }^{4}$ EPOC, UMR5805, CNRS, F33400 Talence, France \\ ${ }^{5}$ Baltic Sea Centre, Stockholm University, Stockholm, Sweden
}

Citation: Virta, L., J. Gammal, M. Järnström, G. Bernard, J. Soininen, J. Norkko, and A. Norkko. 2019. The diversity of benthic diatoms affects ecosystem productivity in heterogeneous coastal environments. Ecology 100(9):e02765. 10.1002/ecy.2765

Abstract. The current decrease in biodiversity affects all ecosystems, and the impacts of diversity on ecosystem functioning need to be resolved. So far, marine studies about diversityecosystem productivity-relationships have concentrated on small-scale, controlled experiments, with often limited relevance to natural ecosystems. Here, we provide a real-world study on the effects of microorganismal diversity (measured as the diversity of benthic diatom communities) on ecosystem productivity (using chlorophyll $a$ concentration as a surrogate) in a heterogeneous marine coastal archipelago. We collected 78 sediment cores at 17 sites in the northern Baltic Sea and found exceptionally high diatom diversity (328 observed species). We used structural equation models and quantile regression to explore relationships between diatom diversity and productivity. Previous studies have found contradictory results in the relationship between microorganismal diversity and ecosystem productivity, but we showed a linear and positive basal relationship between diatom diversity and productivity, which indicates that diatom diversity most likely forms the lowest boundary for productivity. Thus, although productivity can be high even when diatom diversity is low, high diatom diversity supports high productivity. The trait composition was more effective than taxonomical composition in showing such a relationship, which could be due to niche complementarity. Our results also indicated that environmental heterogeneity leads to substantial patchiness in the diversity of benthic diatom communities, mainly induced by the variation in sediment organic matter content. Therefore, future changes in precipitation and river runoff and associated changes in the quality and quantity of organic matter in the sea, will also affect diatom communities and, hence, ecosystem productivity. Our study suggests that benthic microorganisms are vital for ecosystem productivity, and together with the substantial heterogeneity of coastal ecosystems, they should be considered when evaluating the potential productivity of coastal areas.

Key words: Baltic Sea; benthic diatoms; diversity-ecosystem productivity-relationship; microphytobenthos; niche complementarity; organic matter; quantile regression models; spatial heterogeneity; structural equation models.

\section{INTRODUCTION}

Global biodiversity is diminishing at an alarming rate in most ecosystems. Given that biodiversity plays a large functional role in nature, the relationship between biodiversity and ecosystem functioning, such as productivity, has received considerable attention (Tilman et al. 1996, Paquette and Messier 2011), and ecologists widely agree on the existence of positive or unimodal relationships between macro-organismal diversity and ecosystem

Manuscript received 12 October 2018; revised 25 April 2019; accepted 26 April 2019. Corresponding Editor: Helmut Hillebrand.

${ }^{6}$ E-mail: leena.virta@helsinki.fi productivity (Cardinale et al. 2012). Such relationships are based on different presumptions: (1) species exhibit differences in resource use, which allows more diverse communities to utilize resources more completely and thus attain greater productivity, (2) highly productive species are likely to be found in diverse communities (Loreau 1998), or (3) resource availability in the ecosystem limits both diversity and productivity (Gross and Cardinale 2007).

Diversity-productivity - relationships have traditionally been studied using regression analyses and structural equation models that focus on average responses. However, the usefulness of these approaches is restricted by heteroscedasticity (Breusch and Pagan 1979), which is typical for ecological data sets. In scatter plots 
showing ecological relationships, data points are often widely scattered below an upper limit or above a lower limit. This refers to a phenomenon called "factor ceiling," which implies that, although several factors may affect ecosystem productivity, the upper or lower limit is controlled by the variable of interest, namely biodiversity (Thomson et al. 1996). Thus, examining minimum and maximum limits of the data can be a more appropriate approach (Thrush et al. 2006).

Microalgal diatoms play important ecological roles in virtually all aquatic environments (Middelburg et al. 2000). Considering their importance, high abundance and enormous diversity, it is surprising how little attention their effect on ecosystem productivity has received. Nelson et al. (1995) estimated that diatoms account globally for $40 \%$ of total marine primary production of carbon, and benthic diatoms are the most species rich, most abundant and most widely distributed benthic algae (Snoeijs-Leijonmalm et al. 2017). They form a major component of microphytobenthos on sediments, are involved in nutrient cycling and provide a food resource to meio- and macrofaunal grazers (Lohrer et al. 2004, Evrard et al. 2012). The composition and diversity of diatom communities are controlled by the biotic and abiotic environment (e.g., the abundance of grazers, nutrients, habitat characteristics), and the environmental preferences and tolerances of different diatom species are relatively narrow (Soininen 2007). Diatoms also have short life cycles (Jewson 1992). Thus, in regions with sharp spatial and temporal environmental gradients, diatoms exhibit large variation in terms of both community composition and diversity (Passy et al. 1999) and therefore provide an excellent platform for studying diversityproductivity-relationships.

The most commonly used proxy for diversity is taxonomical species richness, but often the diversity can be more effectively defined by the functional trait composition of the community (Hooper et al. 2005). Traits describe organisms' differences in their resource acquisition and tolerance to stressors and consumers (Hodapp et al. 2016), hence reflecting the environmental pressures that communities face. Because traits mediate fluxes of energy and material both directly and indirectly by altering abiotic conditions, the functional trait composition of a community can also be used to predict ecosystem productivity (Chapin et al. 2000, Violle et al. 2014). The relationship between trait diversity and productivity is, however, dependent on the complexity of the environment (Ptacnik et al. 2010). In a homogeneous environment, the scarcity of niches often results in a poor relationship, whereas in a heterogeneous environment with multiple available niches, the relationship is often strongly positive (Ptacnik et al. 2010).

Archipelagos are one of the most heterogeneous and fragmented environments in the marine and brackish ecosystems, with respect to nutrients, primary productivity, and biotic communities (Bonsdorff et al. 1997,
Medina et al. 2007, Gammal et al. 2019). The great diversity of habitats and strong gradients in environmental conditions and biotic communities make archipelagos challenging but interesting study sites for functional biodiversity research. However, so far most of the studies conducted on aquatic and particularly marine communities have been controlled experiments with limited duration, small spatial scale and homogeneous environments (Gamfeldt et al. 2015). Such experiments hold constant many environmental variables that play important roles in natural ecosystems. This makes experiments poorly extrapolatable to nature in complex archipelagos and seafloors at larger scales (Gamfeldt et al. 2015, Gammal et al. 2019). Thus, more realistic research is needed to improve our understanding on the functioning of these vital and heavily used and impacted environments.

In the present study, our aim was to evaluate the role of benthic diatoms in a sedimentary seafloor habitat, one of Earth's most widespread ecosystems, in an archipelago characterized by strong environmental gradients. We studied natural diatom communities and aimed at maximizing the variation of habitat types; this is the first in-depth study of the benthic diatom communities in the study area. As a proxy for benthic microalgal productivity, we used chlorophyll $a$ concentration, which is a widely used indicator for marine productivity in shallow areas (Henson et al. 2010). We also examined diatomgrazer-interactions that naturally occur in the field but are rarely included in controlled experiments (but see Liess et al. 2009). Such a study design is challenging, especially in a complex archipelago with a mosaic of habitats, but also necessary if we want to enhance our understanding of the functioning of real coastal ecosystems (Snelgrove et al. 2014, Gammal et al. 2019). Our specific research questions and hypotheses were (1) Is there a relationship between the diversity of the diatom communities and ecosystem productivity, and is this relationship stronger for functional diversity than for taxonomic diversity? We expected to find a significant relationship between benthic diatom diversity and productivity, because of niche complementarity, sampling effect, or the direct and indirect effects of environment, but we expected it to be stronger for trait diversity than for species diversity (Violle et al. 2014). We also considered the possibility of factor ceiling response in this relationship (Thomson et al. 1996). However, as shown previously in many ecosystems, the shape of the relationship could be positive and linear, unimodal, U-shaped or even negative (Smith 2007). (2) What are the most important environmental variables that drive the species and trait composition in benthic diatom communities? As suggested by the theory of niche complementarity, i.e., complementary resource use leading to more diverse communities, we hypothesized that diatom communities would be sensitive to nutrient concentrations (Passy 2007). We also believed that organic matter (Passy 2010), sediment grain size, abundance of grazers (Passy 2007), 
and abundance of benthic fauna that facilitates diatom communities via, e.g., bioturbation and nutrient transport (Thrush et al. 2006), would have a significant effect. (3) Is there substantial small-scale spatial variation in the diversity of diatom communities? Considering the diversity of habitats and environmental conditions in the coastal archipelago, we hypothesized that diatom species richness would be significantly different among sampling sites in spite of the short spatial distances between them (Hewitt et al. 2008).

\section{Materials And Methods}

\section{Study area and sampling}

Our study area is located on the Finnish coast of the Baltic Sea, close to the Hanko peninsula (Appendix S1: Fig. S1). The coastal zone in this area is characterized by a complex archipelago with a mixture of different habitats from muddy/sandy sheltered bays to rocky, exposed shores. The archipelago area is generally shallow, below $40 \mathrm{~m}$, and very shallow habitats $(<5 \mathrm{~m})$ are common. Thus, the euphotic zone often reaches the bottom, and benthic communities are productive. The salinity is $5-6$ and several large rivers discharge close to the Hanko peninsula, which results in diatom communities with a mixture of brackish and freshwater species.

We conducted the sampling in late summer, 6 August8 September 2014. We collected a total of 78 sediment samples from 17 sites with high natural variability of habitats within and across sites. Within-site sampling was stratified to sample different habitats (bare sediment to varying degrees of vegetation cover and different grain sizes) with samples and video taken to characterize these (see the end of section Study area and sampling). The depth of our sites ranged between 1.7 and $3.9 \mathrm{~m}$, salinity between 5.1 and 5.7, and temperature between $13.6^{\circ} \mathrm{C}$ and $22.5^{\circ} \mathrm{C}$. At each site, we used scuba diving to collect four or five surface sediment samples using cutoff syringes (internal diameter $3.5 \mathrm{~cm}$ ) along a transect of $\sim 20 \mathrm{~m}$. The samples were used for diatom analysis (analyzed from 0 to $0.5 \mathrm{~cm}$ ) and the characterization of the sediment characteristics: grain size (analyzed from 0 to $3 \mathrm{~cm}$ ), organic matter (analyzed from 0 to $0.5 \mathrm{~cm}$ ) and chlorophyll $a$ concentration (analyzed from 0 to $0.5 \mathrm{~cm}$ ). Additionally, we collected an intact sediment core (internal diameter $8.4 \mathrm{~cm} ; 15 \mathrm{~cm}$ of sediment and $15 \mathrm{~cm}$ of bottom water) around every surface sediment sample to obtain bottom-water nutrient concentrations and benthic macrofauna. Each transect was also videoed by scuba divers at a fixed height $(50 \mathrm{~cm})$ above the seafloor, to allow characterization of the vegetation (total cover, species-specific cover, distance to next patch, visible cover of microphytobenthos and drifting algae) and amount of stone cover on the sediment surface (classified 1-3) over increasing spatial scales $(0.25,0.75,1.25$, $1.75,2.25 \mathrm{~m}^{2}$ ) around each sample location.

\section{Laboratory analyses and trait characterization}

We took the sediment cores to the laboratory immediately after sampling, filtered water nutrient samples (Whatman GF/F) and froze all the samples until further processing.

For diatom analyses, we used the surface sediment cores $(0-0.5 \mathrm{~cm})$. We removed organic matter by boiling with hydrogen peroxide $\left(30 \% \mathrm{H}_{2} \mathrm{O}_{2}\right)$ and mounted the cleaned diatoms on slides using Naphrax (Brunel Microscopes Ltd, Wiltshire, UK). Although this method does not allow for the separation of live and dead diatoms, a number of studies have shown that surface sediment diatoms represent the current conditions overall well and thus are a good surrogate for the predominant environment (Weckström et al. 2004). For identification of diatoms, we used a light microscope with $1,000 \times$ magnification. We identified 500 frustules per sample to the lowest possible taxonomic level (typically species level) following Snoeijs (1993), Snoeijs and Vilbaste (1994), Snoeijs and Potapova (1995), and Snoeijs and Kasperovicienè (1996). After the identification of diatoms, we transformed species counts into relative abundances and verified taxonomic names according to AlgaeBase (Guiry 2018). In addition to the species data, we used diatom trait abundance data. We classified diatom species according to their size (biovolume classes: large $>1,000 \mu \mathrm{m}^{3} / \mathrm{small}<1,000 \mu \mathrm{m}^{3}$ ), mobility (mobile/non-mobile), type of attachment (adnate/ pedunculate [which was further divided to pad-attached and stalk-attached]/non-attached), colonization (colonial/ non-colonial), growth form (low-profile/high-profile/ motile/planktonic; Rimet and Bouchez 2012), nitrogenfixing abilities (nitrogen-fixer/non-nitrogen-fixer; Passy 2017), and acid tolerance (tolerant/non-tolerant; Van Dam et al. 1994). To identify traits for each diatom species, we used, in addition to the above-mentioned species and trait literature, Snoeijs et al. (2002) and Diatoms of North America (2019).

We also used the surface sediment cores $(0-0.5 \mathrm{~cm})$ for the analyses of organic matter (loss on ignition, $3 \mathrm{~h}$ at $500^{\circ} \mathrm{C}$ ), chlorophyll $a$ (spectrophotometry) and sediment grain size. For grain size characterization, we treated samples with hydrogen peroxide $\left(6 \% \mathrm{H}_{2} \mathrm{O}_{2}\right)$ to dissolve organic matter and then sieved the samples with $63,125,250,500,1,000$, and $2,000 \mu \mathrm{m}$ sieves, dried the fractions, and calculated the percentage of dry mass of each fraction. To account for the possible confounding effect of including diatoms in the organic matter content, we investigated the contribution of microphytes to the organic matter. The values were low $(0.65-8.13 \%$ for all microphytic organisms) and, thus, we decided to use the entire organic matter content as an explanatory variable in our analyses.

We used the intact sediment cores for bottom-water nutrient analyses. We conducted the analyses with a nutrient auto analyzer (Thermo Scientific Aquakem 250 (Thermo Fisher Scientific Oy, Vantaa, Finland); $\mathrm{NO}_{2}^{-}$, $\mathrm{NO}_{2}{ }^{-}+\mathrm{NO}_{3}{ }^{-}, \mathrm{PO}_{4}{ }^{3-}$, and $\mathrm{Si}$ ), except for $\mathrm{NH}_{4}{ }^{+}$, which 
we analyzed manually. We then sieved $(0.5 \mathrm{~mm})$ the rest of the cores to obtain benthic macrofaunal data and preserved them until analysis in $70 \%$ ethanol. We analyzed the macrofaunal samples using a microscope to determine species richness and the abundances of different species (see Gammal et al. 2019). For the analyses of the relationships between benthic fauna and diatoms, we classified benthic fauna into inhibiting or facilitating species, i.e., "grazers" (amphipods Bathyporeia pilosa, Corophium volutator, Monoporeia affinis, and Pontoporeia femorata, gastropods Hydrobiidae and Theodoxus fluviatilis, bivalves Macoma balthica, and polychaetes Marenzelleria spp., Hediste diversicolor, and Pygospio elegans) and "diatom facilitating fauna" (amphipods Bathyporeia pilosa, Corophium volutator, Monoporeia affinis, and Pontoporeia femorata, bivalves Cerastoderma glaucum and Macoma balthica, and polychaetes Marenzelleria spp. and Hediste diversicolor). With "diatom facilitating fauna", we refer to species that enable the growth of diatoms through their potential of enhancing nutrient effluxes through bioturbation. We are aware of the coexistence of some macrofaunal species in both groups, but we made this decision due to complex relationships in benthic habitats, where macrofaunal species modify the habitat in many ways: they influence biotic interactions but also environmental sediment characteristics by modifying hydrodynamics, biogeochemistry, and particle gradients (Thrush et al. 2006). Thus, the same macrofaunal species can act as both grazers and facilitators.

\section{Statistical analyses}

Scatter plots of diversity-productivity clearly identified one site as an outlier (Appendix S1: Section S1; Appendix S1: Fig. S2), and this was removed from the rest of the analyses. To investigate the potential for within-site correlations in diatom species and trait diversity affecting our results, we ran general linear models (GLM) with site identity included as a categorical explanatory variable. GLM indicated a nonsignificant effect of site for diatom species and trait diversity (Appendix S1: Section S1) and, thus, site was not included as a variable in further analyses including diversity; instead, representations of habitat characteristics were used. We also stress that although these kind of data sets are often biased by within-site correlations, which cannot be totally ruled out in our case either we collected our samples from sites with high natural within-site variation of habitats and deliberately sampled different habitats. Therefore, we believe that our analyses are not negatively affected by within-site correlations, nor are they pseudoreplicates.

As many of our environmental variables were correlated, we reduced correlations and the number of variables using principal component analysis (PCA). PCA was run on all explanatory environmental variables (organic matter, sediment grain size, mud content, $\mathrm{NO}_{2}{ }^{-}$, $\mathrm{NO}_{2}{ }^{-}+\mathrm{NO}_{3}{ }^{-}, \mathrm{NH}_{4}{ }^{+}, \mathrm{PO}_{4}{ }^{3-}, \mathrm{Si}$, abundance of grazers, abundance of diatom facilitating fauna, amount of stones, and vegetation cover), with the first two axes explaining $72.4 \%$ of the variability. The most important environmental variables on PCA axis 1 were vegetation cover, mud content, grain size and organic matter, and together these explained $93.4 \%$ of the variation on PCA axis 1 . The most important factors on PCA axis 2 were stone cover, the abundance of grazers and the abundance of diatom facilitating fauna, and together these explained $98.8 \%$ of the variation on PCA axis 2 .

To investigate direct and indirect relationships between environmental variables, diatom diversity and ecosystem productivity, we used piecewise structural equation models (SEM; Lefcheck 2018). PCA axes 1 and 2 scores were used to represent the environmental characteristics. To represent abundance-based diatom species and trait diversity, we used Simpson's diversity index (Simpson 1949), because this index is not biased by sampling size (Chase and Knight 2013; see Appendix S1: Table S1 for trait abundance table). We chose chlorophyll $a$ concentration to represent ecosystem productivity. We constructed initial full models of hypothesized paths between all variables and considered PC1 and PC2 as exogenous variables, that is, variables that exist only as predictors in the network. From the initial models, we eliminated nonsignificant paths stepwise. We considered models with nonsignificant $P$ values $(>0.05)$ as candidate models and chose the models with lowest AIC (Akaike 1974) as the best-fit models (see Appendix S1: Table S2 for AIC and $P$ values of all potential models).

SEMs focus on average responses. Due to the heteroscedastic nature of our data, we considered it would be useful to study the relationship between diatom species and trait diversity and ecosystem productivity using quantile regression models (Koenker and Hallock 2001) with the lower boundary, i.e., the fifth percentile. The statistical properties of the quantile regression models have been thoroughly described by Cade et al. (1999, 2005). Quantile regression models minimize the asymmetrically weighted sum of residual errors and are insensitive to heteroscedasticity. With specific, selected quantiles, these models can be used to reveal trends that would be hidden with mean regression models. In ecological data, data points in scatter plots are commonly widely scattered beneath an upper limit or above a lower limit, and the edges of a scatter plot in both the maximum and minimum directions can be useful in showing a limit in the response variable that is controlled only by the explanatory variable of interest (Thrush et al. 2003).

Next, we studied the effects of individual variables on diatom species and trait diversity with distance-based redundancy analysis (dbRDA) using Bray-Curtis distance for species composition and Gower's distance for trait composition (Legendre and Anderson 1999). DbRDA is a constrained method that allows ecologically meaningful measures. We assessed multicollinearity among the 
variables by determining variance inflation factors (VIF; O'Brien 2007) and considered values of VIF $>10$ to represent high collinearity. Due to high VIF, mud content was omitted from dbRDA analyses. To consider withinsite correlations in diatom community composition, we included site identity as a categorical explanatory variable in the dbRDA analyses. Prior to dbRDA, we logtransformed $\left(\log _{10}\right.$ for $\mathrm{NH}_{4}{ }^{+}, \mathrm{Si}$, chl $a$, and grain size; $\log _{10}(x+1)$ for $\mathrm{NO}_{2}{ }^{-}, \mathrm{NO}_{2}{ }^{-}+\mathrm{NO}_{3}{ }^{-}, \mathrm{PO}_{4}{ }^{3-}$, organic matter and vegetation cover), or square-root-transformed (abundance of grazers, abundance of diatom facilitating fauna) environmental variables to reduce their skewed distributions. We conducted dbRDA on Hellinger-transformed diatom data (Legendre and Gallagher 2001).

We used hierarchical clustering to find groups of observations that share similar characteristics (Murtagh 1985). We divided our samples into groups according to the significant environmental variables indicated by dbRDA (organic matter, $\mathrm{NO}_{2}{ }^{-}, \mathrm{NH}_{4}{ }^{+}$, abundance of grazers, grain size, $\mathrm{PO}_{4}{ }^{3-}$, and $\mathrm{Si}$ for species, and organic matter, $\mathrm{NO}_{2}{ }^{-}$, abundance of grazers, grain size, $\mathrm{PO}_{4}{ }^{3-}$, and $\mathrm{Si}$ for traits).

We continued by applying species accumulation curves to study the observed species richness and estimated total species richness of the whole diatom data and of the groups constructed by the hierarchical clustering method. Because the groups contained different numbers of samples, we used random sampling methods to ensure comparable species accumulation curves. We constructed the species accumulation curves with the function specaccum. We used the method "random," which adds sites in random order, with 999 permutations. We also extrapolated the total species richness of each group using a first-order jackknife estimator of total species richness (Heltshe and Forrester 1983). To test if diatom species and trait compositions significantly differ between the groups constructed by the hierarchical clustering method, we ran analysis of similarities (ANOSIM) with Bray-Curtis distance for species and Gower's distance for traits (Clarke 1993). ANOSIM is a distribution-free analogue of one-way ANOVA, where values range between -1 and 1, 0 indicating random grouping. We also used the similarity percentages (SIMPER) test (Clarke 1993) to analyze which traits vary most between the groups. The SIMPER test is based on Bray-Curtis distance and measures the contribution of each trait to the between-group effect (Warton et al. 2012).

All statistical analyses were conducted in the R environment (R Development Core Team 2018) using packages dendextend (Galili 2018), piecewiseSEM (Lefcheck 2018), quantreg (Koenker 2018), vegan (Oksanen 2018), and visreg (Breheny and Burchett 2018).

\section{Results}

The final SEM with diatom species diversity explained $15 \%$ of variation in ecosystem productivity and indicated that diatom species diversity was controlled by PCA axis 1 (Fig. 1a). The other paths in the model were nonsignificant. The final SEM with diatom trait diversity explained $15 \%$ of variation in ecosystem productivity and indicated that diatom trait diversity was controlled by PCA axis 1 , and ecosystem productivity was controlled by diatom trait diversity (Fig. 1b).

When exploring the relationship between the diatom diversity and productivity, the linear quantile regression models showed a significant lower boundary, i.e., the fifth percentile, relationship with both species and trait diversity (Fig. 2). This positive relationship was remarkably stronger for trait data than for species data.

In the dbRDA model for the diatom species data, the first axis explained $14.6 \%$ of variation and the second axis $7.1 \%$ of variation. The most significant $(P<0.001)$ environmental variables were sediment organic matter, and $\mathrm{NO}_{2}{ }^{-}$and $\mathrm{NH}_{4}{ }^{+}$in the water column (Appendix S1: Fig. S3, Appendix S1: Table S3). In dbRDA for the diatom trait data, the first axis explained $28.5 \%$ of variation and second axis $8.4 \%$ of variation. The most significant $(P<0.001)$ environmental variable was organic matter (Appendix S1: Fig. S3, Appendix S1: Table S3). The dbRDA also showed strong relationships between environmental variables and traits. Large and high-growing (pad-attached, high-profile, pedunculate, colonial) traits were common in samples with high organic matter content and small grain size, whereas low-profile and adnate traits were common in samples with high abundance of grazers. Site identity appeared as significant $(P=0.012)$ for the species composition, but nonsignificant $(P=0.261)$ for the trait composition.

Hierarchical cluster analyses divided the samples into three groups (Appendix S1: Fig. S4). Due to high significance of sediment organic matter content shown by dbRDA, groups are hereafter referred to as high organic matter (red samples in Appendix S1: Fig. S4), medium organic matter (green samples in Appendix S1: Fig. S4), and low organic matter (blue samples in Appendix S1: Fig. S4). In the cluster analysis for species, the high organic matter group was also characterized by small grain size, low vegetation cover, and high $\mathrm{PO}_{4}{ }^{3-}$ but low $\mathrm{NO}_{2}{ }^{-}+\mathrm{NO}_{3}{ }^{-}$concentrations, the medium organic matter group by low abundance of grazers and diatom facilitating fauna and high $\mathrm{Si}$ but low $\mathrm{NO}_{2}{ }^{-}, \mathrm{NH}_{4}{ }^{+}$and $\mathrm{PO}_{4}{ }^{3-}$ concentrations, and the low organic matter group by large grain size, high abundance of grazers and diatom facilitating fauna and high $\mathrm{NO}_{2}{ }^{-}+\mathrm{NO}_{3}{ }^{-}, \mathrm{NO}_{2}{ }^{-}$ and $\mathrm{NH}_{4}{ }^{+}$but low $\mathrm{Si}$ concentrations. In the cluster analysis for traits, the high organic matter group was characterized by small grain size, small abundance of grazers and diatom facilitating fauna, and small $\mathrm{NO}_{2}{ }^{-}$, $\mathrm{NO}_{2}{ }^{-}+\mathrm{NO}_{3}{ }^{-}$, and $\mathrm{NH}_{4}{ }^{+}$concentrations, the medium organic matter group by large grain size, large abundance of grazers and diatom facilitating fauna, and high $\mathrm{PO}_{4}{ }^{3-}$ but low $\mathrm{Si}$ concentrations, and the low organic matter group by high Si concentration.

Species accumulation curves were used to investigate the observed and total extrapolated species richness of the whole diatom species data and the species data of 
a

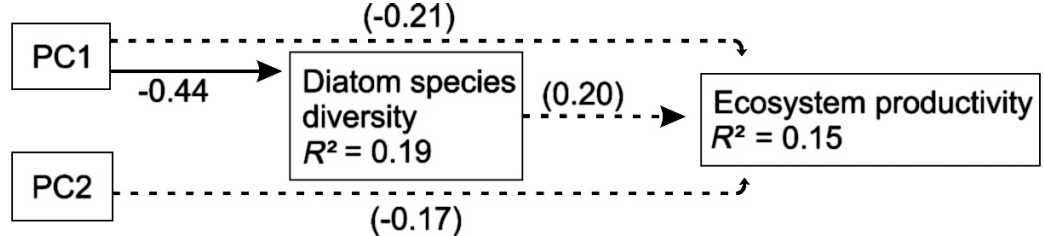

$(-0.17)$

b

\begin{tabular}{|l|l|l|l|}
\hline PC1 & -0.53 & $\begin{array}{l}\text { Diatom trait } \\
\text { diversity } \\
R^{2}=0.28\end{array}$ & 0.39
\end{tabular}$\longrightarrow \begin{aligned} & \text { Ecosystem productivity } \\
& R^{2}=0.15\end{aligned}$

FIG. 1. Best-fit structural equation models (SEM) showing the relationships between environmental variables (PC1 and PC2 axis scores), (a) diatom species diversity (Simpson's diversity index) or (b) diatom trait diversity (Simpson's diversity index), and ecosystem productivity $(\mathrm{chl} a)$. The solid lines denote significant $(P<0.05)$ relationships and dashed lines nonsignificant $(P>0.05)$ relationships that are included in order to achieve significant and well-fitted models; numbers next to lines are standardized coefficients. The most important environmental variables on PC1 were vegetation cover, mud content, grain size, and organic matter, and the most important factors on PC2 were stone cover, the abundance of grazers, and the abundance of diatom facilitating fauna.
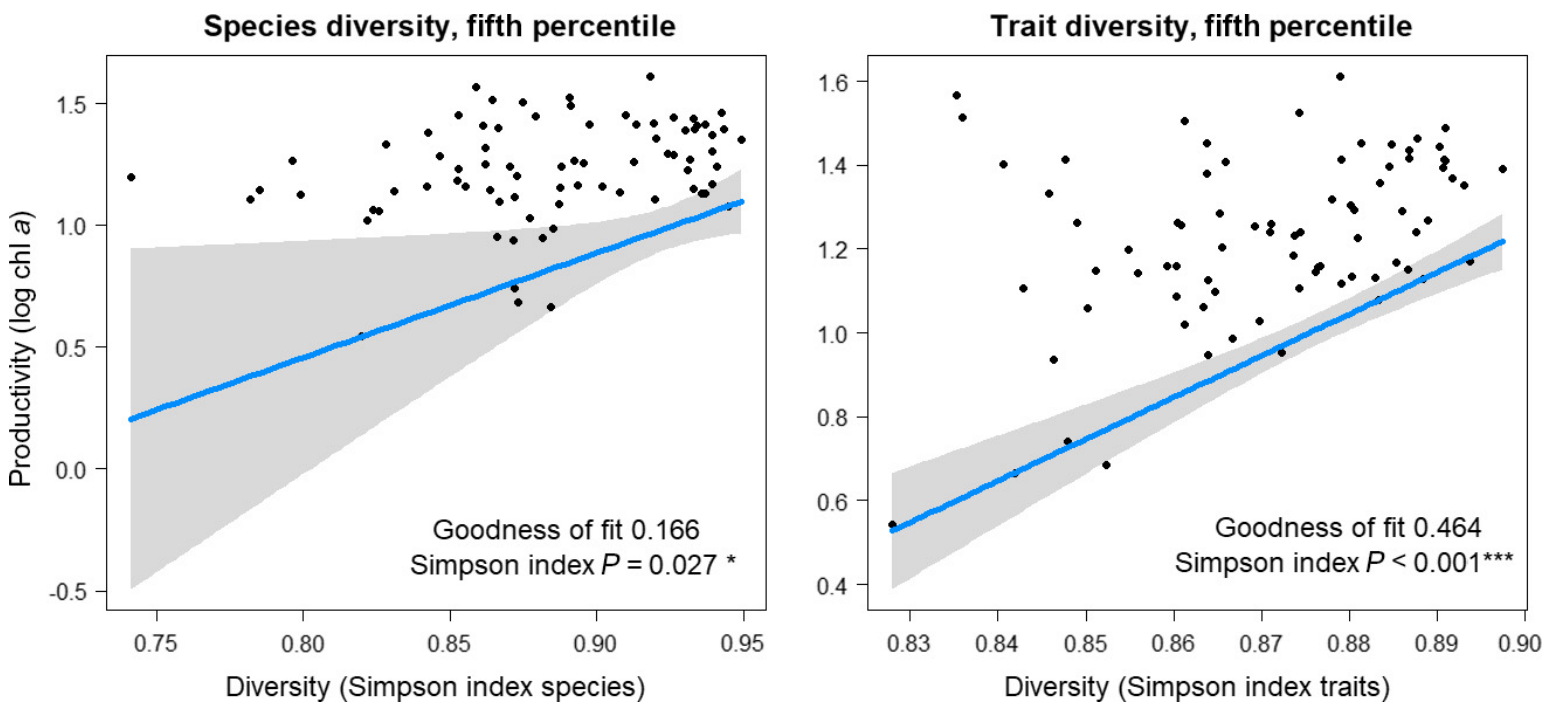

FIG. 2. Quantile regression models between diatom diversity (Simpson's diversity index) and ecosystem productivity (chl $a$, measured as $\mu \mathrm{g} / 1.75 \mathrm{~cm}^{3}$ of surface sediment). The left panel represents diatom species diversity at the fifth percentile, and the right panel represents diatom trait diversity at the fifth percentile. The blue line is the regression line and the shaded area is the confidence interval. *** $P<0.001$; * $P<0.05$.

the three groups formed by hierarchical cluster analysis. We observed that none of the curves reached a horizontal asymptote (Fig. 3). The species accumulation curve of the whole diatom species data showed that our total value of observed species was 328 , but according to the Jackknife 1-procedure, we only found $70.4 \%$ of the species actually present in the sampling area. In the high organic matter group, both the observed species richness (168) and extrapolated total species richness (224) were high. In the medium organic matter group, species richness was medium, whereas the species richness of the low organic matter group was low.

The analysis of similarities (ANOSIM) indicated that both the species and trait compositions significantly differed between the high organic matter, medium organic matter, and low organic matter groups (species $R=0.223, P=0.001$; traits $R=0.239, P=0.001$ ).

Similarity percentages (SIMPER) revealed that the most influential traits $(>10 \%$ in at least one of the high organic matter, medium organic matter, or low organic matter groups) were related to the mobility, attachment, and the ability to form colonies (Appendix S1: Table S4).

\section{Discussion}

\section{Diversity-productivity-relationships}

Productivity is a very important component of ecosystem functioning and a key factor for ecosystem services. We studied the direct and indirect relationships between 

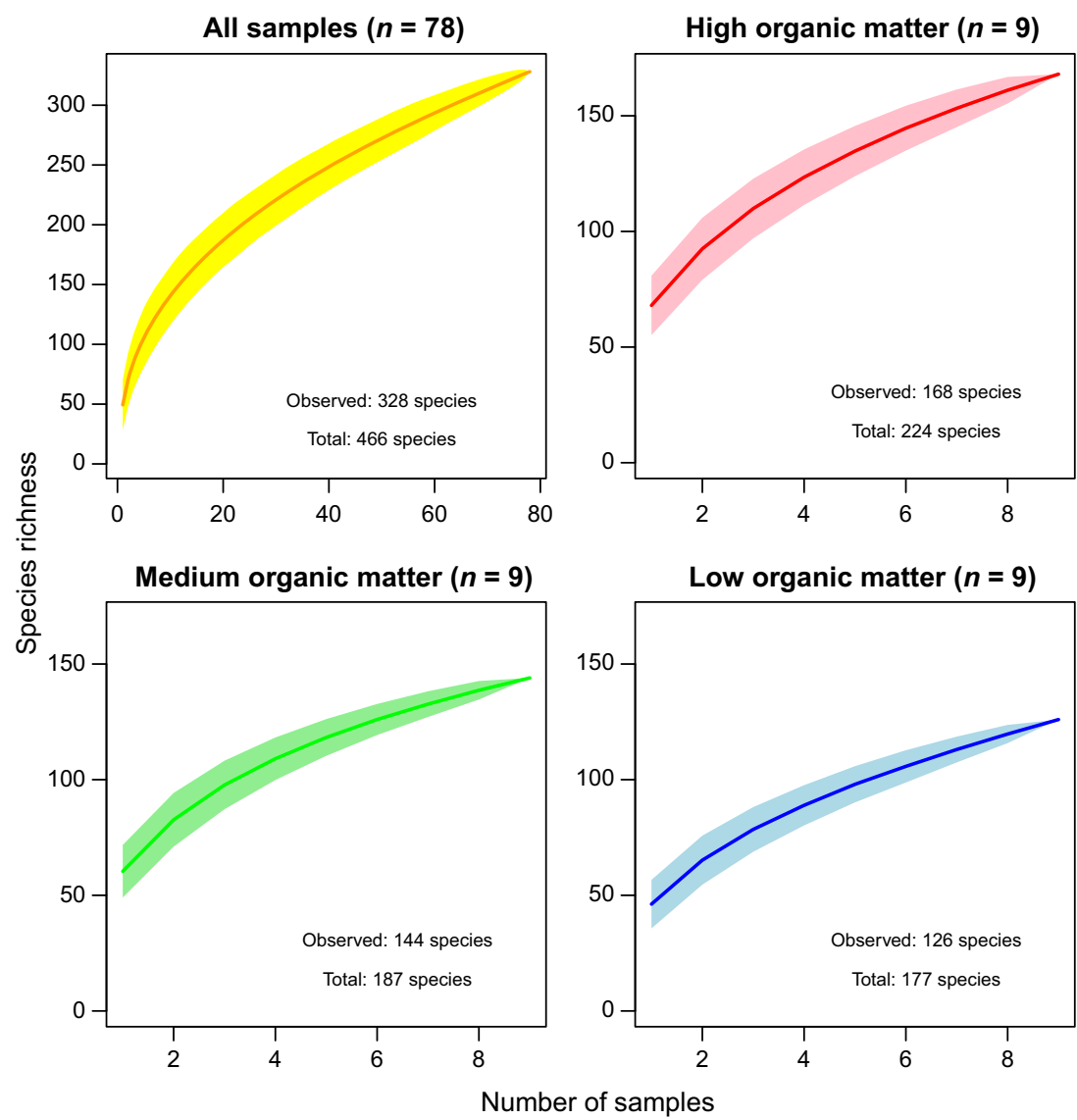

FIG. 3. Species accumulation curves (lines) for the whole diatom data and for the groups formed with hierarchical cluster analysis. The total numbers of species richness refer to the extrapolated richness. The shaded area shows the confidence interval.

environment, diversity of diatom communities, and ecosystem productivity and discovered that environment controls diatom diversity, whereas diatom diversity seems to set the lower boundary to ecosystem productivity. This indicates that productivity can be high even when diatom diversity is low, but high diatom diversity supports high ecosystem productivity. This finding might refer to a phenomenon called "factor ceiling": in ecological data, data points in scatter plots are commonly widely scattered beneath an upper or above a lower limit. This indicates that, although there might be a number of factors affecting the response variable, the extreme limit is controlled by the variable of interest, in our case, diatom diversity (Thomson et al. 1996). To our knowledge, our study is the first to show such a lower boundary relationship between diversity and productivity. We speculate that the potential for high productivity in habitats with low diatom diversity is due to the presence of species capable of high biomass production (Aarssen 1997), or the direct and indirect effects of environmental factors on productivity (Gross and Cardinale 2007). The contribution of other autotrophic organisms, such as cyanobacteria, also needs to be considered. This contribution is varying and highly dependent on the abiotic conditions, but diatoms often dominate in cold and temperate waters, whereas the proportion of cyanobacteria increases with warmer temperatures (Watermann et al. 1999).

To our knowledge, this study is the first to examine the diversity-productivity-relationship with marine or brackish benthic diatoms. However, given the importance of diatoms for global marine primary production, and the results of studies conducted with marine phytoplankton (Lewandowska et al. 2012) and aquatic plants (Duffy 2006), we expected to find a significant relationship between benthic diatom diversity and ecosystem productivity. This hypothesis was indeed confirmed as we found a significant positive linear relationship both in univariate regressions and SEM (for trait diversity). This finding agrees with some other studies in marine environments (Agard et al. 1996), but disagrees with many others that have found, e.g., unimodal or variable relationships (Hall et al. 2000, Boyer et al. 2009).

As we hypothesized, trait diversity was more tightly related to ecosystem productivity than species diversity, both in simple regression and in SEM. Such a positive relationship between traits and productivity could be due to niche complementarity, which implies that the different trait groups occupy different niches and use resources in a 
complementary way, thus resulting in a more effective production (Kahmen et al. 2006). Although definite evidence for niche complementarity cannot be obtained from observational studies, many studies have documented its effect via, e.g., higher productivity in diverse plant communities compared to monocultures (Roscher et al. 2005). We agree, of course, that in addition to niche complementarity, such a positive relationship could be caused by the sampling effect (Loreau et al. 2001) in which highly diverse samples contain some highly productive species, or the direct and indirect effects of environment, such as resource availability (Gross and Cardinale 2007). Thus, although further research is needed to separate these effects in natural communities, our study emphasizes the usefulness of functional traits in diversity-productivity-relationship research.

Although we found a linear positive lower quantile relationship, our results indicate substantial variation in the diversity-ecosystem productivity-relationship. This is in agreement with earlier studies (Boyer et al. 2009, Norkko et al. 2015) suggesting that the effect of biodiversity on ecosystem functioning is highly dependent on the environmental context (Gammal et al. 2019). So far, most of the studies on marine diversity-productivityrelationships have been conducted as relatively simple, controlled experiments (Gamfeldt et al. 2015). However, benthic coastal ecosystems are, due to the availability of nutrients and light, highly productive and diverse systems, which was highlighted by the observed 328 diatom species in our data. Such complex environments and diverse communities are extremely difficult to include in controlled experiments (Thrush et al. 2012). Furthermore, the significance of diversity-productivity-relationships increases with growing spatial scale (Mittelbach et al. 2001), which often makes experiments insufficient in scale for investigating these relationships. Thus, our findings emphasize the importance of field studies to better understand the effect of microbial diversity for the functioning of marine ecosystems.

\section{The effect of environment on species and trait composition of diatom communities}

Environmental factors explained the trait composition of diatom communities more effectively than the species composition. However, almost the same combination of environmental factors-organic matter content, nutrients, benthic fauna, grain size-affected both species and trait composition. Despite the inclusion of a number of environmental factors, part of the variation in diatom community composition was left unexplained. We speculate that this may be due to, e.g., unmeasured habitat features or trace metal concentrations that are known to affect diatom diversity (Chappell et al. 2019).

Our analyses indicated that organic matter content is by far the most significant factor in controlling diatom communities. In our sampling sites, organic matter content is high in sheltered bays with negligible wave action.
At these sites, high organic matter content leads to diverse diatom communities and, in combination with small grain size and low abundance of grazers, facilitates the occurrence of prominent diatom species, i.e., species that exhibit large, high-profile, and colonial traits. The importance of organic matter content for microorganisms has been recognized before (Marín-Spiotta et al. 2014), but organic matter is quite rarely included as an environmental variable in benthic microorganismal studies. The importance of organic matter is related to its nutritive values to microbes, such as diatoms that live in intimate contact with sediment grains (Admiraal and Peletier 1979). Microbes consume organic matter during heterotrophic growth (Asmala et al. 2018), which many diatom species are capable of in light-limited conditions, such as in the sediment (Admiraal and Peletier 1979). Due to the high importance of organic matter to microbes, changes in microbial community composition are anticipated in the future: river flow is the main driver for organic matter concentrations in surface waters (Erlandsson et al. 2008), and climate scenarios estimate increased precipitation and river runoff in the northern Baltic Sea area (Kjellström and Ruosteenoja 2007).

Our results suggested that all the analyzed nutrients (nitrogen, phosphate, silicate) are important for diatoms, as also documented before (Passy 2007). Phosphorus often dominates as a limiting nutrient for primary production in freshwater ecosystems (Schindler 1977), while nitrogen limitation is more common in marine ecosystems (Howarth and Marino 2006). However, our finding of the combined limitation of nitrogen and phosphorus is also common (Elser et al. 2007). The importance of silica as a limiting nutrient in the Baltic Sea has increased due to eutrophication and consequent high productivity of silicate-consuming diatoms (Conley et al. 2008).

Our results show increasing diatom diversity towards smaller sediment grain size, which may be due to larger surface area, higher organic matter content, and lower grazing pressure in finer sediments (Rusch et al. 2003). However, the effect of grain size on microphytobenthic production may not be straightforward: microphytobenthic biomass is generally higher on fine sediments, but primary production can be equally high or even higher on coarse sediments (Billerbeck et al. 2007). This may be related to, e.g., different life strategies of microphytobenthos on fine and coarse sediments, or to more frequent disturbance and resuspension events on coarse sediments (see Billerbeck et al. 2007 for more thorough consideration). In addition to the high species diversity, our samples with small grain size were characterized by large and high-profile traits. This may be due to different grain size preferences between species (Admiraal and Peletier 1979) and lower abundance of grazers (Hall and Anderson 2013) and lower grazer activity (De Troch et al. 2006) in substrates with small grain size.

Benthic macrofauna affects diatom growth in two opposite ways: grazing removes diatom cells, whereas bioturbation transports nutrients to the surface layers of 
sediment where it is available for microphytobenthos (Thrush et al. 2006). In our study, high abundances of both grazers and diatom facilitating fauna increased the importance of both negative and positive effects of benthic fauna. Grazing pressure was also connected to the trait composition: samples with high abundance of grazers were dominated by low-profile and adnate species. This agrees with the findings of Jyrkänkallio-Mikkola et al. (2016), who noted that the number of grazers and low growth form of diatoms are positively correlated.

\section{Small-scale spatial variation in diatom communities}

Here, coastal benthos exhibited substantial patchiness in the diversity and community composition. Most of the studies showing similar heterogeneity of communities in archipelagos have been conducted in deep sea archipelagos (Johnson and Black 2006), where great depth and strong currents between islands lead to isolated habitats (Darwin 1859, Watts and Johnson 2004). Our study highlights the role of archipelagos as hotspots of patchiness of biotic communities also in the shallow coastal zone, where disjunction of habitats is the main driver for the formation of patches.

\section{ConClusions}

Microorganisms are vital to all ecosystems, but our knowledge about the relationship between their diversity and ecosystem productivity is still poor. Although controlled experiments can provide mechanistic insight into diversity-productivity-relationships, results are rarely directly applicable to complex natural ecosystems, such as marine coastal environments. Our field campaign on a heterogeneous sedimentary seafloor revealed the importance of microorganisms for aquatic ecosystems and showed that diatom diversity most likely forms the lowest boundary for ecosystem productivity. To our knowledge, this result has not previously been observed. Our findings also indicate substantial patchiness in the diversity of benthic communities in coastal archipelagos, which should be considered when modelling these important environments, which are exposed to increasing anthropogenic pressure. The most significant factor for the patchiness in diatom diversity seems to be the variation in sediment organic matter content. Therefore, presumed future changes in precipitation and river runoff patterns that are likely to change the quality and quantity of organic matter in the sea, will also affect diatom communities and, hence, ecosystem productivity.

\section{ACKNOWLedGements}

We thank Judi Hewitt and Aleksandra Lewandowska for advice on statistical analyses, Emmi Hänninen for video analyses, and Hanna Halonen and the trainees at Tvärminne Zoological Station for valuable practical assistance. This study was funded by Walter and Andrée de Nottbeck foundation (L. Virta, J. Gammal, G. Bernard), University of Helsinki (J. Norkko), and the BONUS COCOA project, which was supported by BONUS (Art 185), funded by the EU and the Academy of Finland (A. Norkko) and the Academy of Finland (project ID 294853). We thank Simon Thrush and one anonymous reviewer for comments that significantly improved the paper.

\section{Literature Cited}

Aarssen, L. W. 1997. High productivity in grassland ecosystems: effected by species diversity or productive species? Oikos 80:183-184.

Admiraal, W., and H. Peletier. 1979. Influence of organic compounds and light limitation on the growth-rate of estuarine benthic diatom. British Phycological Journal 14:197-206.

Agard, J. B. R., R. H. Hubbard, and J. K. Griffith. 1996. The relation between productivity, disturbance and the biodiversity of Caribbean phytoplankton: applicability of Huston's dynamic equilibrium model. Journal of Experimental Marine Biology and Ecology 202:1-17.

Akaike, H. 1974. A new look at the statistical model identification. IEEE Transactions on Automatic Control 19:716723.

Asmala, E., L. Haraguchi, H. H. Jakobsen, P. Massicotte, and J. Carstensen. 2018. Nutrient availability as major driver of phytoplankton-derived dissolved organic matter transformation in coastal environment. Biogeochemistry 137:93-104.

Billerbeck, M., H. Roy, K. Bosselmann, and M. Huettel. 2007. Benthic photosynthesis in submerged Wadden Sea intertidal flats. Estuarine Coastal and Shelf Science 71:704-716.

Bonsdorff, E., E. M. Blomqvist, and A. Norkko. 1997. Coastal eutrophication: causes, consequences and perspectives in the Archipelago areas of the northern Baltic Sea. Estuarine Coastal and Shelf Science 44:63-72.

Boyer, K. E., J. S. Kertesz, and J. F. Bruno. 2009. Biodiversity effects on productivity and stability of marine macroalgal communities: the role of environmental context. Oikos 118:1062-1072.

Breheny, P., and W. Burchett. 2018. Package visreg. https://cran. r-project.org/web/packages/visreg/visreg.pdf

Breusch, T. S., and A. R. Pagan. 1979. Simple test for heteroscedasticity and random coefficient variation. Econometria 47:1287-1294.

Cade, B. S., J. W. Terrell, and R. L. Schroeder. 1999. Estimating effects of limiting factors with regression quantiles. Ecology 80:311-323.

Cade, B. S., B. R. Noon, and C. H. Flather. 2005. Quantile regression reveals hidden bias and uncertainty in habitat models. Ecology 86:786-800.

Cardinale, B. J., et al. 2012. Biodiversity loss and its impact on humanity. Nature 486:59-67.

Chapin, F. S., et al. 2000. Consequences of changing biodiversity. Nature 405:234-242.

Chappell, P. D., E. V. Armbrust, K. A. Barbeau, R. M. Bundy, J. W. Moffett, J. Vedamati, and B. D. Jenkins. 2019. Patterns of diatom diversity correlate with dissolved trace metal concentrations and longitudinal position in the northeast Pacific coastal-offshore transition zone. Marine Ecology Progress Series 609:69-86.

Chase, J. M., and T. M. Knight. 2013. Scale-dependent effect sizes of ecological drivers on biodiversity: why standardised sampling is not enough. Ecology Letters 16:17-26.

Clarke, K. R. 1993. Non-parametric multivariate analyses of changes in community structure. Australian Journal of Ecology 18:117-143.

Conley, D. J., et al. 2008. Past, present and future state of the biogeochemical Si cycle in the Baltic Sea. Journal of Marine Systems 73:338-346. 
Darwin, C. 1859. On the origin of species. John Murray, London, UK.

De Troch, M., L. Houthoofd, V. Chepurnov, and A. Vanreusel. 2006. Does sediment grain size affect diatom grazing by harpacticoid copepods? Marine Environmental Research 61:265-277.

Diatoms of North America. 2019. https://diatoms.org/

Duffy, E. 2006. Biodiversity and the functioning of seagrass ecosystems. Marine Ecology Progress Series 311:233-250.

Elser, J. J., M. E. S. Bracken, E. E. Cleland, D. S. Gruner, W. S. Harpole, H. Hillebrand, J. T. Ngai, E. W. Seabloom, J. B. Shurin, and J. E. Smith. 2007. Global analysis of nitrogen and phosphorus limitation of primary producers in freshwater, marine and terrestrial ecosystems. Ecology Letters 10:1135-1142

Erlandsson, M., I. Buffam, J. Folster, H. Laudon, J. Temnerud, G. A. Weyhenmeyer, and K. Bishop. 2008. Thirty-five years of synchrony in the organic matter concentrations of Swedish rivers explained by variation in flow and sulphate. Global Change Biology 14:1191-1198.

Evrard, V., M. Huettel, P. L. M. Cook, K. Soetaert, C. H. R. Heip, and J. J. Middelburg. 2012. Importance of phytodetritus and microphytobenthos for heterotrophs in a shallow subtidal sandy sediment. Marine Ecology Progress Series 455:13-31.

Galili, T. 2018. Extending "dendrogram" functionality in R. https://CRAN.R-project.org/package=dendextend

Gamfeldt, L., J. S. Lefcheck, J. E. K. Byrnes, B. J. Cardinale, J. E. Duffy, and J. N. Griffin. 2015. Marine biodiversity and ecosystem functioning: what's known and what's next. Oikos 124:252-265.

Gammal, J., M. Järnström, G. Bernard, J. Norkko, and A. Norkko. 2019. Environmental context mediates biodiversityecosystem functioning relationships in coastal soft-sediment habitats. Ecosystems 22:137-151.

Gross, K., and B. J. Cardinale. 2007. Does species richness drive community production or vice versa? Reconciling historical and contemporary paradigms in competitive communities. American Naturalist 170:207-220.

Guiry, M. D. 2018. AlgaeBase. http://algaebase.org/

Hall, L. W., and R. D. Anderson. 2013. The relationship of metals, bifenthrin, physical habitat metrics, grain size, total organic carbon, dissolved oxygen and conductivity to $\mathrm{Hya}$ lella sp. abundance in urban California streams. Journal of Environmental Science and Health Part A: Toxic/Hazardous Substances \& Environmental Engineering 48:360-369.

Hall, S. J., S. A. Gray, and Z. L. Hammett. 2000. Biodiversityproductivity relations: an experimental evaluation of mechanisms. Oecologia 122:545-555.

Heltshe, J. F., and N. E. Forrester. 1983. Estimating species richness by using the jackknife procedure. Biometrics 39:1-11.

Henson, S. A., J. L. Sarmiento, J. P. Dunne, L. Bopp, I. Lima, S. C. Doney, J. John, and C. Beaulieu. 2010. Detection of anthropogenic climate change in satellite records of ocean chlorophyll and productivity. Biogeosciences 7:621-640.

Hewitt, J., S. F. Thrush, and P. D. Dayton. 2008. Habitat variation, species diversity and ecological functioning in a marine system. Journal of Experimental Marine Biology and Ecology $366: 116-122$.

Hodapp, D., H. Hillebrand, B. Blasius, and A. B. Ryabov. 2016. Environmental and trait variability constrain community structure and the biodiversity-productivity relationship. Ecology 97:1463-1474.

Hooper, D. U., et al. 2005. Effects of biodiversity on ecosystem functioning: a consensus of current knowledge. Ecological Monographs 75:3-35.

Howarth, R. W., and R. Marino. 2006. Nitrogen as the limiting nutrient for eutrophication in coastal marine ecosystem: evolving views over three decades. Limnology and Oceanography 51:364-376.

Jewson, D. H. 1992. Size-reduction, reproductive strategy and the life-cycle of a centric diatom. Philosophical Transactions of the Royal Society B 336:191-213.

Johnson, M. S., and R. Black. 2006. Islands increase genetic subdivision and disrupt patterns of connectivity of intertidal snails in a complex archipelago. Evolution 60:2498-2506.

Jyrkänkallio-Mikkola, J., J. Heino, and J. Soininen. 2016. Beta diversity of stream diatoms at two hierarchical spatial scales: implication for biomonitoring. Freshwater Biology 61:239250.

Kahmen, A., C. Renker, S. B. Unsicker, and N. Buchmann. 2006. Niche complementarity for nitrogen: an explanation for the biodiversity and ecosystem functioning relationship? Ecology 87:1244-1255.

Kjellström, E., and K. Ruosteenoja. 2007. Present-day and future precipitation in the Baltic Sea region as simulated in a suite of regional climate models. Climatic Change 81:281291

Koenker, R. 2018. Package quantreg. https://cran.r-project.org/ web/packages/quantreg/quantreg.pdf

Koenker, R., and K. F. Hallock. 2001. Quantile regression. Journal of Economic Perspectives 15:143-156.

Lefcheck, J. 2018. Package piecewiseSEM. https://cloud.r-pro ject.org/web/packages/piecewiseSEM/piecewiseSEM.pdf

Legendre, P., and M. J. Anderson. 1999. Distance-based redundancy analysis: testing multispecies responses in multifactorial ecological experiments. Ecological Monographs 69:1-24.

Legendre, P., and E. D. Gallagher. 2001. Ecologically meaningful transformations for ordination of species data. Oecologia 129:271-280.

Lewandowska, A. M., P. Breithaupt, H. Hillebrand, H. G. Hoppe, K. Jurgens, and U. Sommer. 2012. Responses of primary productivity to increased temperature and phytoplankton diversity. Journal of Sea Research 72:87-93.

Liess, A., K. Lange, F. Schulz, J. J. Piggott, C. D. Matthaei, and C. R. Townsend. 2009. Light, nutrients and grazing interact to determine diatom species richness via changes to productivity, nutrient state and grazer activity. Journal of Ecology 97:326-336

Lohrer, A. M., S. F. Thrush, and M. M. Gibbs. 2004. Bioturbators enhance ecosystem function through complex biogeochemical interactions. Nature 431:1092-1095.

Loreau, M. 1998. Biodiversity and ecosystem functioning: a mechanistic model. Proceedings of the National Academy of Sciences USA 95:5632-5636.

Loreau, M., et al. 2001. Ecology-biodiversity and ecosystem functioning: current knowledge and future challenges. Science 294:804-808

Marín-Spiotta, E., K. E. Gruley, J. Crawford, E. E. Atkinson, J. R. Miesel, S. Greene, C. Cardona-Correa, and R. G. M Spencer. 2014. Paradigm shifts in soil organic matter research affect interpretations of aquatic carbon cycling: transcending disciplinary and ecosystem boundaries. Biogeochemistry 117:279-297.

Medina, A., J.-C. Brêthes, J.-M. Sévigny, and B. Zakardjian. 2007. How geographic distance and depth drive ecological variability and isolation of demersal fish communities in an archipelago system (Cap Verde, Eastern Atlantic Ocean). Marine Ecology-An Evolutionary Perspective 28:404-417.

Middelburg, J. J., C. Barraguet, H. T. S. Boschker, P. M. J. Herman, T. Moens, and C. H. R. Heip. 2000. The fate of intertidal microphytobenthos carbon: an in situ C-13-labeling study. Limnology and Oceanography 45:1224-1234.

Mittelbach, G. G., C. F. Steiner, S. M. Scheiner, K. L. Gross, H. L. Reynolds, R. B. Waide, M. R. Willig, S. I. Dodson, and L. 
Gough. 2001. What is the observed relationship between species richness and productivity? Ecology 82:2381-2396.

Murtagh, F. 1985. Multidimensional clustering algorithms. Physica-Verlag, Heidelberg, Germany.

Nelson, D. M., P. Treguer, M. A. Brzezinki, A. Leynaert, and B. Queguiner. 1995. Production and dissolution of biogenic silica in the ocean-revised global estimates, comparison with regional data and relationship to biogenic sedimentation. Global Biogeochemical Cycles 9:359-372.

Norkko, J., J. Gammal, J. E. Hewitt, A. B. Josefson, J. Carstensen, and A. Norkko. 2015. Seafloor ecosystem function relationships: in situ patterns of change across gradients of increasing hypoxic stress. Ecosystems 18:1424-1439.

O'Brien, R. M. 2007. A caution regarding rules of thumb for variance inflation factors. Quality and Quantity 41:673-690.

Oksanen, J. 2018. Package vegan. https://cran.r-project.org/ web/packages/vegan/vegan.pdf

Paquette, A., and C. Messier. 2011. The effect of biodiversity on tree productivity: from temperate to boreal forests. Global Ecology and Biogeography 20:170-180.

Passy, S. I. 2007. Diatom ecological guilds display distinct and predictable behavior along nutrient and disturbance gradients in running waters. Aquatic Botany 86:171-178.

Passy, S. I. 2010. A distinct latitudinal gradient of diatom diversity is linked to resource supply. Ecology 91:36-41.

Passy, S. I. 2017. Framework for community functioning: synthesis of stress gradient and resource partitioning concepts. PEERJ 5:e3885.

Passy, S., Y. Pan, and R. L. Lowe. 1999. Ecology of the major periphytic diatom communities from the Mesta River, Bulgaria. International Review of Hydrobiology 84:129-174.

Ptacnik, R., S. D. Moorthi, and H. Hillebrand. 2010. Hutchinson reversed, or why there need to be so many species. Advances in Ecological Research 43:1-43.

R Development Core Team. 2018. The R project for statistical computing. The R Foundation, Vienna, Austria. http://www. r-project.org

Rimet, F., and A. Bouchez. 2012. Life-forms, cell-sizes and ecological guilds of diatoms in European rivers. Knowledge and Management of Aquatic Ecosystems 406:01.

Roscher, C., V. M. Temperton, M. Scherer-Lorenzen, M. Schmitz, J. Schumacher, B. Schmid, N. Buchmann, W. W. Weisser, and E. D. Schulze. 2005. Overyielding in experimental grassland communities - irrespective of species pool or spatial scale. Ecology Letters 8:419-429.

Rusch, A., M. Huettel, C. E. Reimers, G. L. Taghon, and C. M. Fuller. 2003. Activity and distribution of bacterial populations in Middle Atlantic Bight shelf sands. Fems Microbiology Ecology 44:89-100.

Schindler, D. W. 1977. Evolution of phosphorus limitation in lakes. Science 195:260-262.

Simpson, E. H. 1949. Measurement of diversity. Nature 163:688.

Smith, V. H. 2007. Microbial diversity-productivity relationships in aquatic ecosystems. FEMS Microbiology Ecology 62:181-186

Snelgrove, P. V. R., S. F. Thrush, D. H. Wall, and A. Norkko. 2014. Real world biodiversity-ecosystem functioning: a seafloor perspective. Trends in Ecology \& Evolution 29:398-405.

Snoeijs, P. 1993. Intercalibration \& distribution of diatom species in the Baltic Sea volume. Volume 1. Opulus Press, Uppsala, Sweden.
Snoeijs, P., and J. Kasperovicienè. 1996. Intercalibration and distribution of diatom species in the Baltic Sea Volume 4. Opulus Press, Uppsala, Sweden.

Snoeijs, P., and M. Potapova. 1995. Intercalibration and distribution of diatom species in the Baltic Sea. Volume 3. Opulus Press, Uppsala, Sweden.

Snoeijs, P., and S. Vilbaste. 1994. Intercalibration and distribution of diatom species in the Baltic Sea. Volume 2. Opulus Press, Uppsala, Sweden.

Snoeijs, P., S. Busse, and M. Potapova. 2002. The importance of diatom cell size in community analysis. Journal of Phycology 38:265-272.

Snoeijs-Leijonmalm, P., H. Schubert, and T. Radziejewska. 2017. Biological oceanography of the Baltic Sea. Springer Netherlands, Dordrecht, The Netherlands.

Soininen, J. 2007. Environmental and spatial control of freshwater diatoms - a review. Diatom Research 22:473-490.

Thomson, J. D., G. Weiblen, B. A. Thomson, S. Alfaro, and P. Legendre. 1996. Untangling multiple factors in spatial distributions: lilies, gophers, and rocks. Ecology 77:16981715.

Thrush, S. F., J. E. Hewitt, A. Norkko, P. E. Nicholls, G. A. Funnell, and J. I. Ellis. 2003. Habitat change in estuaries: predicting broad-scale responses of intertidal macrofauna to sediment mud content. Marine Ecology Progress Series 263:101112.

Thrush, S. F., J. E. Hewitt, M. Gibbs, C. Lundquist, and A. Norkko. 2006. Functional role of large organisms in intertidal communities: community effects and ecosystem function. Ecosystems 9:1029-1040.

Thrush, S. F., J. E. Hewitt, and A. M. Lohrer. 2012. Interaction networks in coastal soft-sediments highlight the potential for change in ecological resilience. Ecological Applications 22:1213-1223.

Tilman, D., D. Wedin, and J. Knops. 1996. Productivity and sustainability influenced by biodiversity in grassland ecosystems. Nature 379:718-720.

Van Dam, H., A. Mertens, and J. Sinkeldam. 1994. A coded checklist and ecological indicator values of freshwater diatoms from the Netherlands. Netherlands Journal of Aquatic Ecology 28:117-133.

Violle, C., P. B. Reich, S. W. Pacalae, B. J. Enquist, and J. Kattge. 2014. The emergence and promise of functional biogeography. Proceedings of the National Academy of Sciences USA 111:13690-13696.

Warton, D. I., S. T. Wright, and Y. Wang. 2012. Distance-based multivariate analyses confound location and dispersion effects. Methods in Ecology and Evolution 3:89-101.

Watermann, F., H. Hillebrand, G. Gerdes, W. E. Krumbein, and U. Sommer. 1999. Competition between benthic cyanobacteria and diatoms as influenced by different grain sizes and temperatures. Marine Ecology Progress Series 187:77-87.

Watts, R. J., and M. S. Johnson. 2004. Estuaries, lagoons and enclosed embayments: habitats that enhance population subdivision of inshore fishes. Marine and Freshwater Research 55:641-651.

Weckström, K., S. Juggins, and A. Korhola. 2004. Quantifying background nutrient concentrations in coastal waters: A case study from an urban embayment of the Baltic Sea. Ambio 33:324-327. 